\title{
THERMAL BEHAVIOR AND PYROLYSIS OF AVGAMASYA ASPHALTITE
}

\author{
Y. TONBUL ${ }^{(a) *}$, A. SAYDUT ${ }^{(b)}$ \\ (a) Faculty of Education, Dicle University \\ TR-21280 Diyarbakir, Turkey \\ (b) Faculty of Engineering and Architecture, Dicle University \\ TR-21280 Diyarbakir, Turkey
}

\begin{abstract}
The pyrolysis and thermal behavior of Avgamasya (SE Anatolia, Turkey) asphaltite was performed using thermogravimetric analysis at atmospheric pressure in dynamic nitrogen atmosphere $\left(30 \mathrm{~mL} \mathrm{~min}^{-1}\right)$. Four heating rate profiles $\left(2.5,5,10\right.$ and $\left.20 \mathrm{~K} \mathrm{~min}^{-1}\right)$ were applied, with a final temperature $1123 \mathrm{~K}$. Two-stage decomposition was observed in the experiments. During the stage 1, when the temperature is lower, only weaker chemical bonds are destroyed and some small gaseous molecules are produced. During the stage 2, when temperature is higher, the cracking is faster and stronger chemical bonds are broken, so that larger molecules decompose into small molecules in the gaseous phase. Kissinger (differential) and Coats-Redfern (integral) methods were applied to thermogravimetric data to obtain kinetic parameters (activation energy and Arrhenius constant).
\end{abstract}

\section{Introduction}

Asphaltite is a petroleum-originated substance formed by metamorphism. The low oxygen content of asphaltites $(<2 \%)$ is the best evidence about its origin. It is a hard and a blackish material, with a relatively high softening point of about $200-315^{\circ} \mathrm{C}$. Asphaltite is soluble in carbon disulfide. Turkish asphaltite deposits of Mesozoic-Cenozoic age contain high amounts of quartz, pyrite, carbonates and clay minerals [1]. The range of asphaltite application is wide: production of paint and varnish, automobile tires, electrical isolation and ink and in road construction. Like crude oil asphaltite yields, after some refining operations, synthetic gas, liquid fuel, ammonia, and sulfur. It can also be used in power plants for production of electrical energy [2].

General Directorate of Mineral Research and Exploration has determined over 60 million tonnes of asphaltite reserves in an area of $1700 \mathrm{~km}^{2}$ in

\footnotetext{
* Corresponding author: e-mail ytonbul@dicle.edu.tr
} 
Turkey. Avgamasya-Mardin (14 million tonnes) is the largest asphaltite deposit in Turkey located at southeastern Anatolia. Different veins of asphaltic materials have different physical and chemical characteristics depending on the location of asphaltic material, geological formation and degree of metamorphosis. Turkish asphaltite is mostly classified between asphaltite and asphaltic pyrobitumen with respond to thermal maturation. Average values for the asphaltite reserves are reported to be water (1-5.3 wt.\%), ash (33-45 wt.\%), sulfur (4.1-6.4 wt.\%), volatile matter (24-40 wt.\%), fixed carbon (47-59 wt.\%), hydrogen (3.2-5.6 wt.\%), and solubility in $\mathrm{CS}_{2}(4.9-30 \mathrm{wt} . \%)[2,3]$.

Thermal analysis is defined by the International Confederation for Thermal Analysis as including all techniques which enable to measure physical properties of a substance and/or of its reaction products as a function of temperature while the substance is subjected to a controlled temperature program. The most common thermal analysis techniques are differential scanning calorimetry (DSC), thermogravimetry (TG/DTG) and differential thermal analysis [4].

In recent years the application of thermogravimetry, differential scanning calorimetry and derivative thermogravimetry to study the combustion and pyrolysis behavior of fossil fuels has gained a wide acceptance among researchers, being of exceptional significance for industry and for economy [5]. Duz with coworkers [6] studied the pyrolysis kinetics and chemical composition of Hazro coal. The factors, such as heating rate and particle size, influencing kinetic data were reviewed. Also, kinetic parameters of decomposition reaction were calculated using Coats-Redfern method. Kök and Pamir [7] performed the study on combustion kinetics of three oil samples using DSC. Activation energies were calculated using thermogravimetric data by ASTM and Roger\&Morris methods. Steiner et al. [8] developed a method to determine the course of heating value and heat production rate of volatiles during pyrolysis of solid fuel particles using thermogravimetric analyzer and flow-calorimeter. They calculated heating value of volatiles from heat production rate and mass loss of particle using a new method. Hicyilmaz and Altun [1] studied the improvement of combustion properties of asphaltite. They stated that ash content of asphaltite was reduced from $44.86 \%$ to $31.44 \%$ by gravity concentration method with a $75 \%$ combustible recovery. The thermogravimetric data obtained were used to determine activation energy of asphaltite pyrolysis. Altun et al. [9] investigated the effect of particle size and heating rate on pyrolysis of Silopi asphaltite. Pyrolysis characteristics of the samples were analyzed using TG/DTG curves. Also, pyrolysis kinetics of samples was determined using Arrhenius-type kinetic model and ASTM methods. The results showed that pyrolysis kinetics is significantly affected by sample particle size and heating rate. Jaber and Probert [10] investigated pyrolysis and gasification kinetics of Jordanian oil shales. They stated that gasification and pyrolysis of investigated shales complied with first-order kinetics: activation energy and 
temperature at which the maximum reactivity rate occurred decreased slightly as the shale-particle size was reduced. Jing-Song et al. [11] studied pyrolysis of asphalt using thermogravimetric analysis at atmospheric pressure and nitrogen as the ambient gas. They established that pyrolysis of asphalt is describable by a two-stage first-order model. Li and Yue [12] analyzed four different oil shale samples with the aid of thermogravimetric analyzer at a constant heating rate of $5{ }^{\circ} \mathrm{C} \mathrm{min}{ }^{-1}$. Kinetic parameters of oil shale pyrolysis were determined on the basis of TG data. The relationship between kinetic parameters was investigated. Pyrolysis studies have provided important quantitative information on identity, composition and structure of asphaltites [13].

Pyrolysis is the general name of the process of production of various gaseous, liquid and solid products at heating of fossil fuels, especially of coal, in the absence of oxygen. This process, also called carbonization, is one of the most important processes of converting lignite, bituminous coal, peat or similar fuels into high-quality fuel char or a number of gaseous and liquid by-products, that can be utilized in chemical industry as supplements for petroleum-based raw materials [9].

This paper presents the data on thermal behavior and pyrolysis kinetics of Avgamasya asphaltite calculated basing on thermogravimetric analysis of fractions of different particle size and applying Kissinger and Coats-Redfern method.

\section{Experimental}

The Avgamasya asphaltite from SE Anatolia region of Turkey was used in this study. After drying in an oven at $105^{\circ} \mathrm{C}$, the samples were crushed into three fractions of different particle size $(0.250-0.600,0.125-0.250$ and $0.071-0.125 \mathrm{~mm}$ ) in a jaw breaker (Retsch BB 1/A) and ground in a rotor beater mill (Retsch SRZ).

Sieve analysis is one of the oldest methods to determine size distribution of solid particles. The Retsch 3B model test-sieving machine (Tyler series sieves: $3360-71 \mu \mathrm{m}$ ) was used, and the grain-size classes were weighed using an analytical balance.

Elemental analysis of the samples was carried out using Carlo Erba model 1108 elemental analyzer calibrated with standard compounds using the $\mathrm{K}$ factor calculation.

Pyrolysis experiments were carried out by non-isothermal thermogravimetry using Shimadzu TGA-50 analyzer. Thermogravimetric experimental procedure involves placing the sample (ca. $14 \mathrm{mg}$ ) into a platinum crucible and heating in in ambient nitrogen atmosphere to $1123 \mathrm{~K}$ at four different linear heating rates of $2.5,5,10$ and $20 \mathrm{~K} \mathrm{~min}^{-1}$ at nitrogen flow rate of $30 \mathrm{~mL} \mathrm{~min}^{-1}$. All the experiments were carried out at least twice for reproducibility. 


\section{Results and discussion}

Heating value, ash content, and sulfur distribution of the asphaltite samples were determined according to ASTM $(3174,3175$, D2492-77) procedures. Analysis data are presented in Table 1.

Table 1. Elemental and proximate analysis of Avgamasya asphaltite

\begin{tabular}{|l|c|c|r|}
\hline \multicolumn{1}{|c|}{ Proximate analysis } & $\%$ & Elemental analysis & \multicolumn{1}{c|}{$\%$} \\
\hline Moisture & 1.26 & $\mathrm{C}$ & 51.44 \\
Ash & 39.07 & $\mathrm{H}$ & 3.87 \\
Volatile matter & 34.59 & $\mathrm{~N}$ & 0.90 \\
Fixed carbon & 25.08 & $\mathrm{~S}$ (total) & 6.89 \\
Calorific value $(\mathrm{MJ} / \mathrm{kg})$ & 46.81 & & \\
\hline
\end{tabular}

TG/DTG data of samples demonstrated two stages of mass loss as a function of temperature. TG and DTG curves obtained using asphaltite samples of three different size are presented in Figures 1-6, respectively. It can be seen that initial and final temperatures and temperatures of maximum weight loss rate are shifted to higher temperatures when heating rate is increased. These shifts can be attributed to the variations in the rate of heat transfer with the change in the heating rate and the short exposure time to a particular temperature at higher heating rates, as well as the effect of the decomposition kinetics [10]. The corresponding experimental data are also given in Table 2. No correlation between the temperatures and particle size of asphaltite samples was observed.

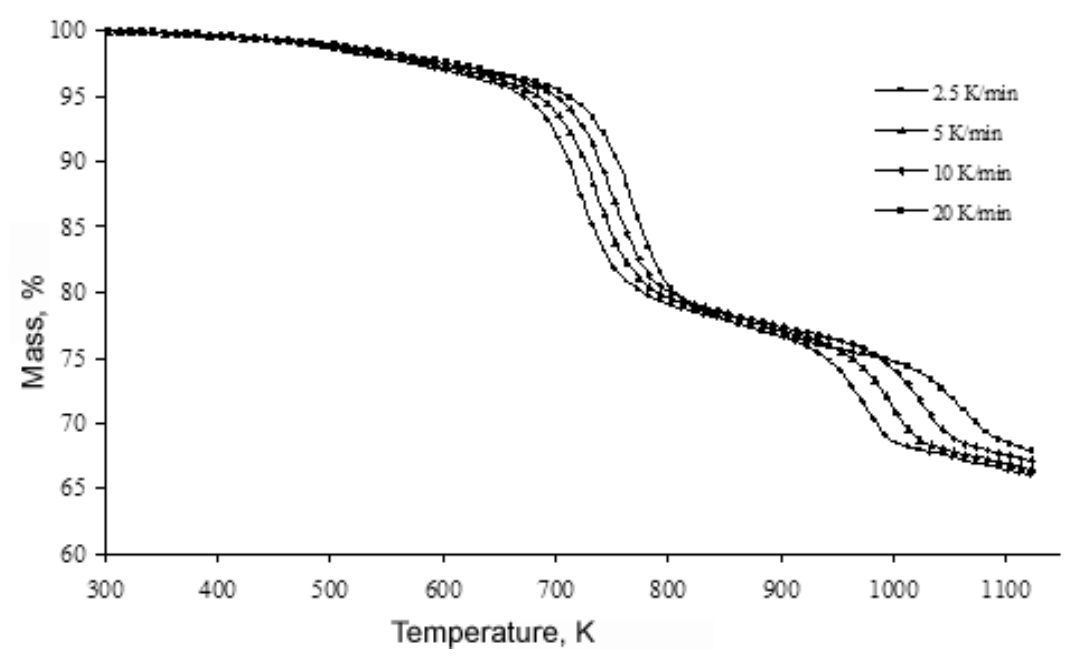

Fig. 1. TG thermogram of Avgamasya asphaltite (particle size $0.250-0.600 \mathrm{~mm}$ ). 


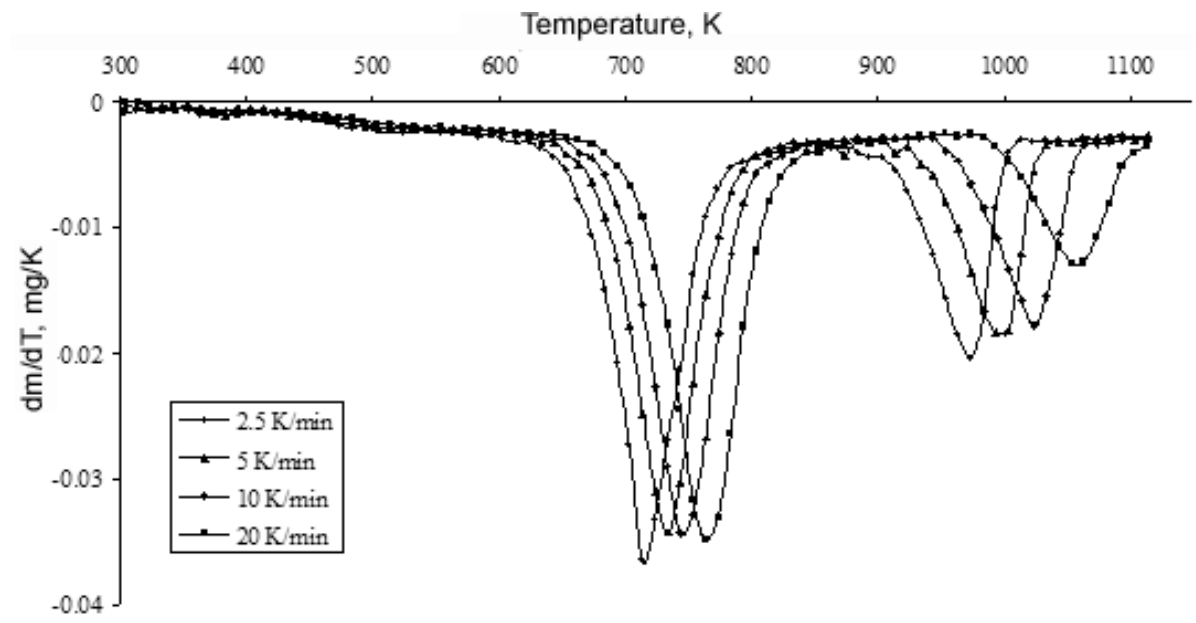

Fig. 2. DTG thermogram of Avgamasya asphaltite (particle size $0.250-0.600 \mathrm{~mm}$ ).

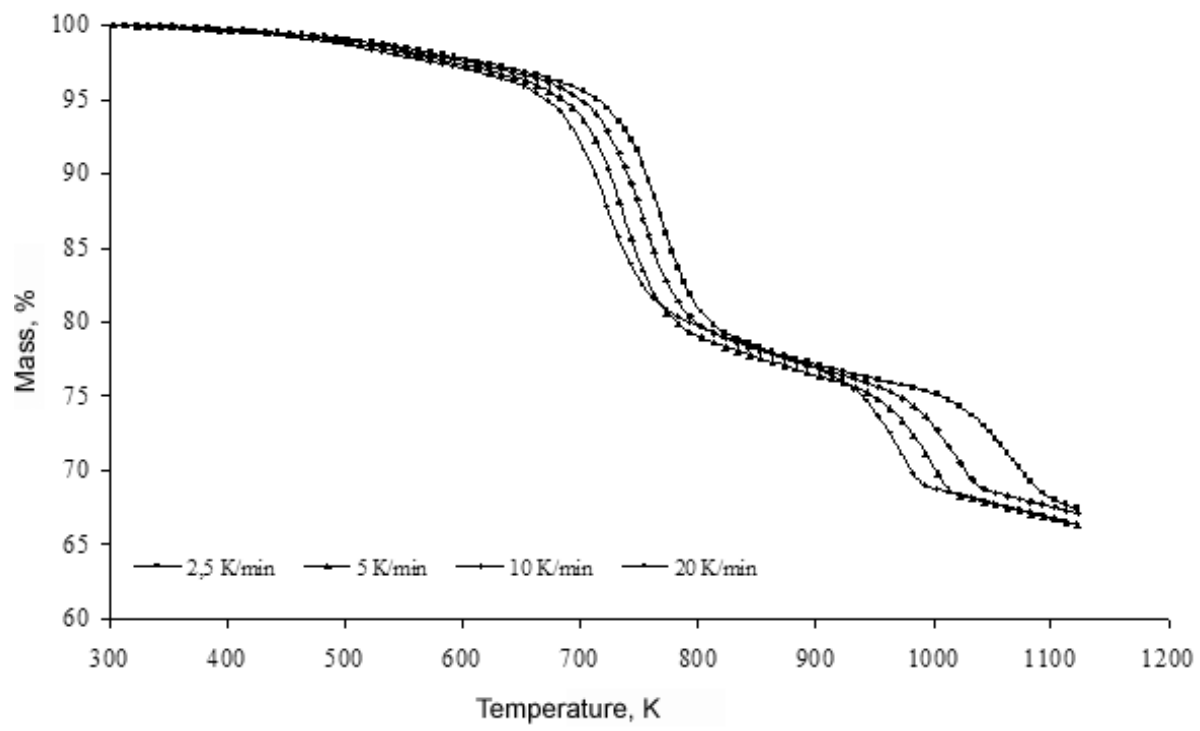

Fig. 3. TG thermogram of Avgamasya asphaltite (particle size $0.125-0.250 \mathrm{~mm}$ ). 


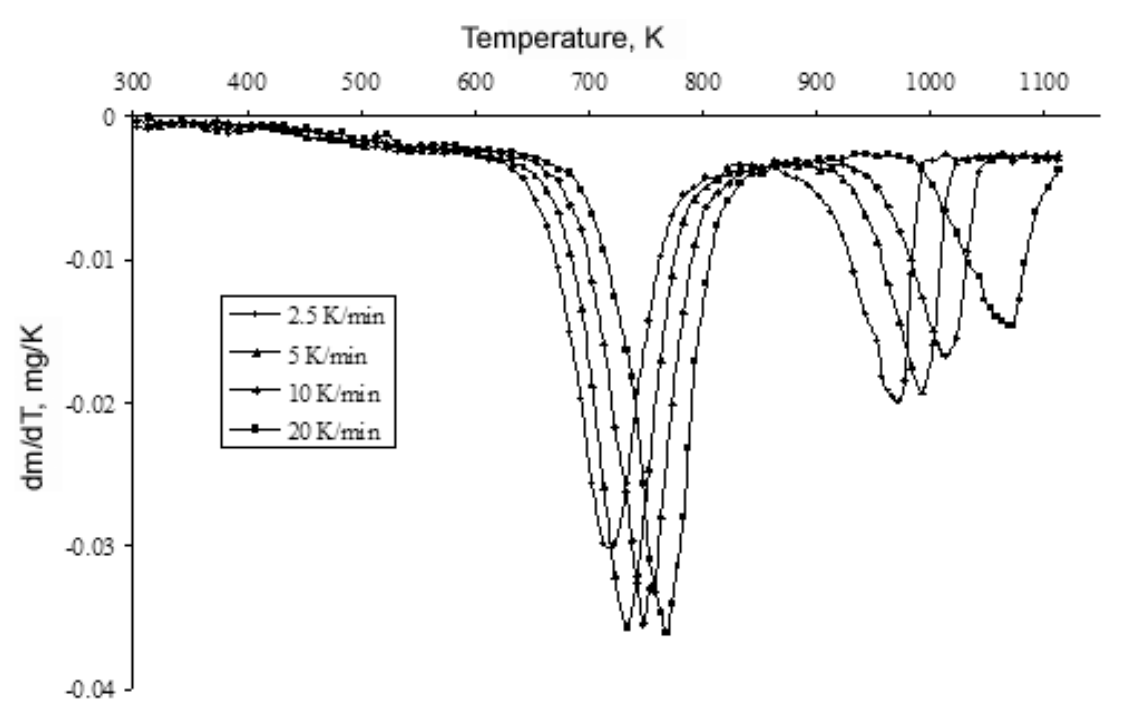

Fig. 4. DTG thermogram of Avgamasya asphaltite (particle size $0.125-0.250 \mathrm{~mm}$ ).

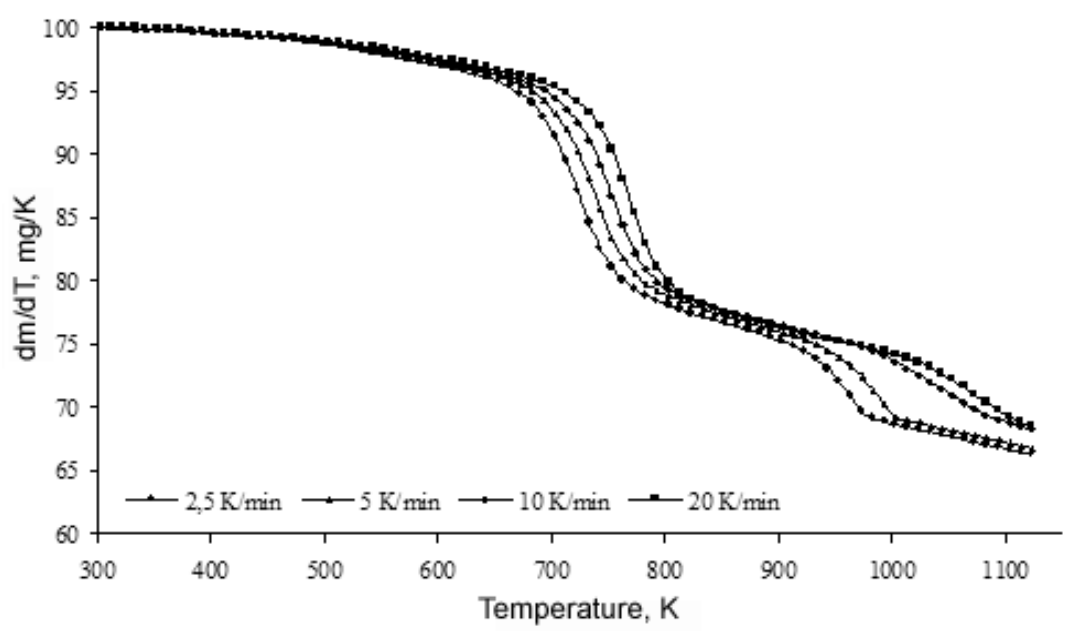

Fig. 5. TG thermogram of Avgamasya asphaltite (particle size 0.071-0.15 mm). 


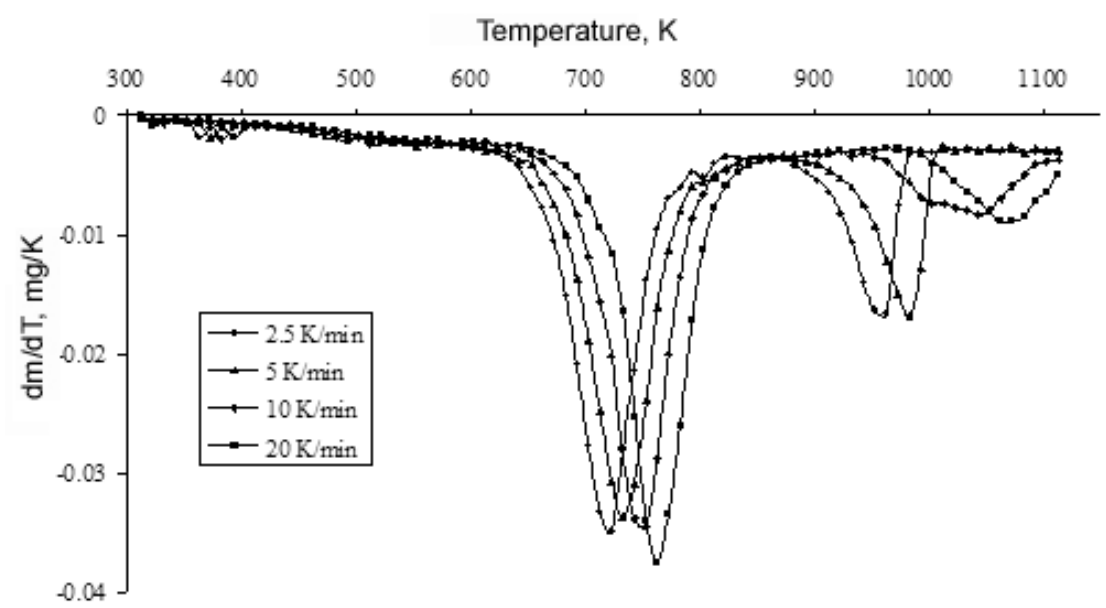

Fig. 6. TG thermogram of Avgamasya asphaltite (particle size 0.071-0.125 mm).

Table 2. Temperatures of initial and final weight loss of asphaltite samples in studied pyrolysis conditions

\begin{tabular}{|c|c|cccc|ccc|}
\hline \multirow{2}{*}{$\begin{array}{c}\text { Particle size, } \\
\mathrm{mm}\end{array}$} & Heating rate, & \multicolumn{3}{|c|}{ Stage 1} & \multicolumn{3}{c|}{ Stage 2} \\
\cline { 3 - 8 } & $\mathrm{K} \mathrm{min}^{-1}$ & $T_{i}, \mathrm{~K}$ & $T_{f}, \mathrm{~K}$ & $T_{M}, \mathrm{~K}$ & $T_{i}, \mathrm{~K}$ & $T_{f}, \mathrm{~K}$ & $T_{M}, \mathrm{~K}$ \\
\hline \multirow{5}{*}{$0.250-0.600$} & 2.5 & 638.4 & 800.4 & 723.1 & 911 & 1028.8 & 980.8 \\
& 5 & 644 & 809.7 & 737.9 & 932.6 & 1047.5 & 1004.8 \\
& 10 & 655.5 & 832.4 & 752.7 & 955.8 & 1076.9 & 1031.3 \\
& 20 & 668.9 & 861.9 & 772.2 & 990.3 & 1118.2 & 1055.6 \\
\hline \multirow{5}{*}{$0.125-0.250$} & 2.5 & 610.5 & 823 & 721.7 & 890.2 & 1002.9 & 976.2 \\
& 5 & 630.6 & 824.6 & 739.1 & 920.7 & 1029.4 & 1000.8 \\
& 10 & 649.9 & 841.8 & 754.1 & 939.3 & 1054.5 & 1023.2 \\
& 20 & 671 & 854.4 & 772.4 & 988 & 1110 & 1050.3 \\
\hline & 2.5 & 632.1 & 798.8 & 720.7 & 885.1 & 989.9 & 965.2 \\
$0.071-0.125$ & 5 & 641.3 & 824.5 & 739.1 & 916 & 1011.4 & 990.3 \\
& 10 & 655.2 & 837.7 & 755.5 & 954.3 & 1102.2 & 1028.4 \\
& 20 & 672 & 855.6 & 771.2 & 985.6 & 1123 & 1065.2 \\
\hline
\end{tabular}

It can be seen that there are two peaks apparent in the DTG figures. The first one is called primary devolatization region (stage 1), and it occurs in the range of $600-800 \mathrm{~K}$, while the second one is called secondary gasification region (stage 2) that occurs in the range of $900-1100 \mathrm{~K}$. It is known that asphaltic substances contain large molecules, including all kinds of hydrocarbons and other compounds. During the stage 1, when the temperature is lower, only weaker chemical bonds are destroyed and some small gaseous molecules are produced. During the stage 2, the temperature is higher, the cracking is faster and stronger chemical bonds are broken, so that larger molecules decompose into small gaseous molecules [11]. 
Reaction rate is defined as the derivative of conversion with respect to time. In thermogravimetric measurements, the conversion is typically calculated as:

$$
\alpha=\frac{W_{t}-W_{f}}{W_{0}-W_{f}},
$$

where $W_{t}, W_{0}$ and $W_{f}$ are the actual, the initial and final weights of the sample, respectively. Kinetic information can be extracted from dynamic experiments by means of various methods. Kinetic studies assume that the isothermal rate of conversion, $d \alpha / d t$, is a linear function of the reactant concentration loss and of the temperature-independent rate constant, $k$, and a temperature-independent function of the conversion, $\alpha$, that is:

$$
\frac{d \alpha}{d t}=k f(\alpha),
$$

where $f(\alpha)$ is the reaction model that depends on the mechanism of the degradation reaction. Discussions about the form and validity of this approach have been the concern of many investigators. The function $k$ is always described by the Arrhenius expression:

$$
k=A e^{-\frac{E}{R T}},
$$

where $A$, the pre-exponential factor (Arrhenius constant), is assumed to be independent of temperature, $E$ is activation energy, $T$ absolute temperature, and $R$ gas constant. The combination of (2) and (3) gives the following relationship:

$$
\frac{d \alpha}{d t}=A f(\alpha) e^{-\frac{E}{R T}} .
$$

If the sample temperature is changed by a controlled and constant heating rate, $\beta=d T / d t$, the variation in the degree of conversion can be analyzed as a function of temperature, which depends on the time of heating. Therefore, the reaction rate may be written as follows:

$$
\frac{d \alpha}{d t}=\frac{d \alpha}{d T} \frac{d T}{d t}=\beta \frac{d \alpha}{d t} .
$$

A combination of (4) and (5) leads to

$$
\frac{d \alpha}{d T}=\frac{A}{\beta} e^{-\frac{E}{R T}} f(\alpha) .
$$


Integration of this equation from an initial temperature, $T_{0}$, corresponding to a degree of conversion $\alpha_{0}$, to the peak temperature, $T_{p}$, where $\alpha=\alpha_{p}$, gives:

$$
\int_{\alpha_{o}}^{\alpha_{p}} \frac{d \alpha}{f(\alpha)}=\frac{A}{\beta} \int_{T_{0}}^{T_{p}} e^{-\frac{E}{R T}} d T .
$$

If $T_{0}$ is low, it may be reasonably assumed that $\alpha_{0}=0$, and considering that there is no reaction between 0 and $T_{0}$ :

$$
g(\alpha)=\int_{\alpha_{o}}^{\alpha_{p}} \frac{d \alpha}{f(\alpha)}=\frac{A}{\beta} \int_{T_{0}}^{T_{p}} e^{-\frac{E}{R T}} d T,
$$

where $g(\alpha)$ is the integral function of conversion[14].

Analysis of the changes in thermogravimetric data, which are brought about by variation of heating rate, are the basis of the most powerful methods for determination of kinetic parameters.

Coats and Redfern developed an integral method, which can be applied to thermogravimetric data, assuming the order of reactions. The correct order is presumed to lead to the best linear plot, from which the activation energy is determined. The final form of the equation, which is used for the analysis, takes the form

$$
\begin{array}{cc}
\ln \left[\frac{1-(1-\alpha)^{1-n}}{T^{2}(1-n)}\right]=\ln \frac{A R}{\beta E}\left[1-\frac{2 R T}{E}\right]-\frac{E}{R T} \quad \text { for } n \neq 1 \\
\ln \left[\frac{-\ln (1-\alpha)}{T^{2}}\right]=\ln \frac{A R}{\beta E}\left[1-\frac{2 R T}{E}\right]-\frac{E}{R T} \quad \text { for } n=1,
\end{array}
$$

where $\beta$ is the heating rate $\left(\mathrm{K} \mathrm{min}^{-1}\right)[15,16]$.

Thus a plot of $\ln \left[1-(1-\alpha)^{1-n} /\left(T^{2}(1-n)\right)\right]$ vs $1 / T$ should result in a straight line of slope that equals $-E / \mathrm{R}$ for the correct value of reaction order, $n$. In the present study, 60 different reaction orders were assumed between 0.5 and 2.0, and the best correlation coefficients (>0.99) were obtained for $n=1.5$ for stage 1 and $n=1.25$ for stage 2. As example, Coats-Redfern plots for Avgamasya asphaltite (particle size $0.250-0.600 \mathrm{~mm}$, heating rate $2.5 \mathrm{~K} \mathrm{~min}^{-1}$ ) are presented in Figures 7 and 8 for stages 1 and 2, respectively. Calculated kinetic parameters are presented in Table 3. It can be seen that values of activation energy vary from 172.25 to $188.69 \mathrm{~kJ} \mathrm{~mol}^{-1}$ for stage 1 and from 298.84 to $384.13 \mathrm{~kJ} \mathrm{~mol}^{-1}$ for stage 2 . The values of $\ln \mathrm{A}$ vary from 27.43 to $30.38 \mathrm{~min}^{-1}$ for stage 1 and from 35.11 to $46.38 \mathrm{~min}^{-1}$ for stage 2 . Upon comparing the results calculated using Coats-Redfern method, it can be seen that there exist no correlation between kinetic parameters and particle size and heating rate. 


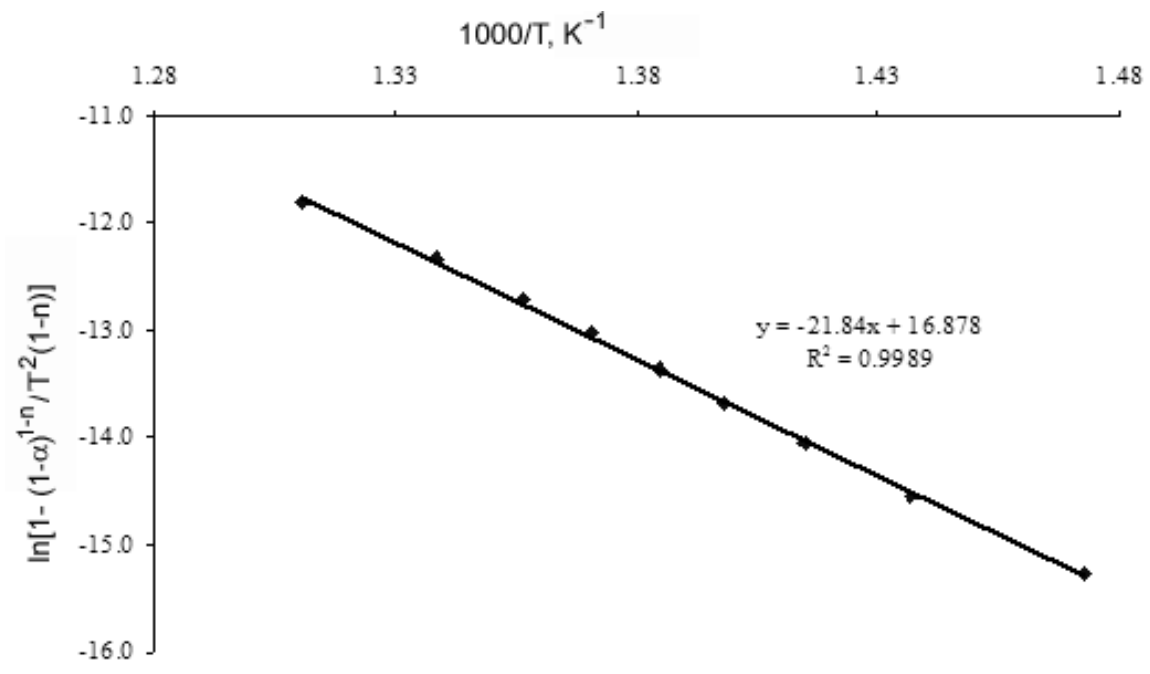

Fig. 7. Coats-Redfern plot of Avgamasya asphaltite (particle size $0.250-0.600 \mathrm{~mm}$, heating rate $2.5 \mathrm{~K} \mathrm{~min}^{-1}$ ) for stage 1 .

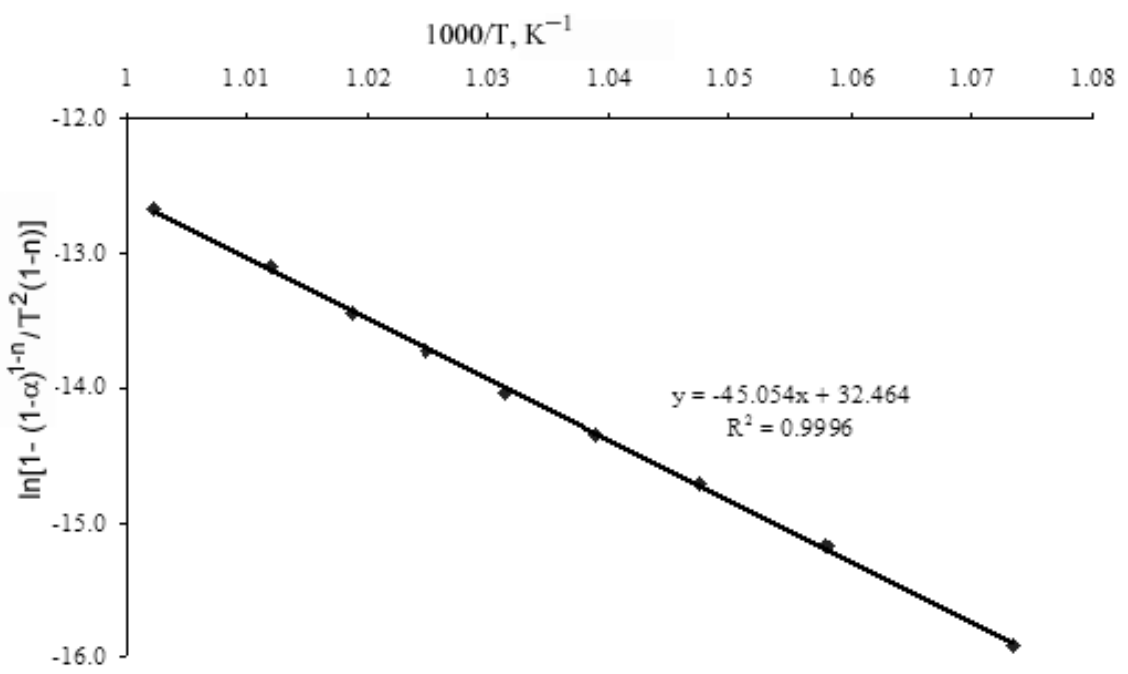

Fig. 8. Coats-Redfern plot of Avgamasya asphaltite (particle size $0.250-0.600 \mathrm{~mm}$, heating rate $2.5 \mathrm{~K} \mathrm{~min}^{-1}$ ) for stage 2 . 
Table 3. Reaction parameters of the Avgamasya asphaltite samples calculated using Coats-Redfern method

\begin{tabular}{|c|c|c|c|c|c|}
\hline \multirow{2}{*}{$\begin{array}{c}\text { Heating rate, } \\
\text { K min }^{-1}\end{array}$} & $\begin{array}{c}\text { Particle size, } \\
\mathrm{mm}\end{array}$ & \multicolumn{2}{|c|}{$\begin{array}{c}\text { Stage 1 } \\
(n=1.5)\end{array}$} & \multicolumn{2}{c|}{$\begin{array}{c}\text { Stage 2 } \\
(n=1.25)\end{array}$} \\
\cline { 3 - 6 } & & $\begin{array}{c}E, \\
\mathrm{~kJ} \mathrm{~mol}^{-1}\end{array}$ & $\begin{array}{c}\ln A, \\
\mathrm{~min}^{-1}\end{array}$ & $\begin{array}{c}E, \\
\mathrm{~kJ} \mathrm{~mol}^{-1}\end{array}$ & $\begin{array}{c}\ln A, \\
\mathrm{~min}^{-1}\end{array}$ \\
\hline 2.5 & $0.250-0.600$ & 181.58 & 28.98 & 374.58 & 45.57 \\
& $0.125-0.250$ & 174.33 & 27.79 & 330.41 & 40.45 \\
& $0.071-0.125$ & 181.88 & 29.14 & 331.86 & 41.02 \\
\hline 5 & $0.250-0.600$ & 184.81 & 29.67 & 384.13 & 46.38 \\
& $0.125-0.250$ & 173.33 & 27.65 & 374.97 & 45.56 \\
& $0.071-0.125$ & 172.25 & 27.43 & 339.01 & 41.09 \\
\hline 10 & $0.250-0.600$ & 188.69 & 30.38 & 380.85 & 45.24 \\
& $0.125-0.250$ & 176.69 & 28.26 & 365.34 & 43.99 \\
& $0.071-0.125$ & 179.91 & 28.81 & 298.84 & 35.11 \\
\hline 20 & $0.250-0.600$ & 187.62 & 30.08 & 369.80 & 42.90 \\
& $0.125-0.250$ & 181.15 & 29.03 & 374.05 & 44.44 \\
& $0.071-0.125$ & 188.18 & 30.18 & 301.67 & 34.59 \\
\hline
\end{tabular}

$n$ - reaction order

Kissinger method has been used to determine the activation energy from plots of the logarithm of the heating rate versus the inverse of the temperature at the maximum reaction rate in constant heating rate experiments.

The activation energy can be determined by Kissinger method without a precise knowledge of the reaction mechanism, using the following equation:

$$
\ln \frac{\beta}{T_{\max }^{2}}=\left\{\ln \frac{A R}{E}+\ln \left[n(1-\alpha)^{n-1}\right]\right\}-\frac{E}{R T_{\max }},
$$

where $\beta$ is the heating rate, $T_{\max }$ the temperature corresponding to the inflection point of the thermal degradation curves which corresponds to the maximum reaction rate, $A$ Arrhenius constant, $\alpha_{\max }$ extent of conversion at $T_{\max }$, and $n$ reaction order. From the plots of $\ln \left(\beta / T_{\max }{ }^{2}\right)$ versus $1 / T_{\max }$ and fitting to a straight line, the activation energy $E$ can be calculated from the slope [17-19].

As example, Kissinger plots for Avgamasya asphaltite (particle size $0.600+0.250 \mathrm{~mm}$ ) are presented in Figures 9 and 10 for stages 1 and 2, respectively. Reaction parameters calculated using Kissinger method are given in Table 4. It can be seen that activation energy values vary from 180.64 to $197.40 \mathrm{~kJ} \mathrm{~mol}^{-1}$ for stage 1 and from 127.76 to $198.78 \mathrm{~kJ} \mathrm{~mol}^{-1}$ for stage 2 . The values of $\ln \mathrm{A}$ were calculated according to reaction ordes 1.5 for stage 1 and 1.25 for stage 2, and they vary from 27.43 to $30.38 \mathrm{~min}^{-1}$ for stage 1 and from 35.11 to $46.38 \mathrm{~min}^{-1}$ for stage 2 . It can be seen that the values of kinetic parameters increase when the particle size decreases during stage 1 . On the other hand, for stage 2 , there is a decrease in the activation 
energy values with decreasing particle size. No correlation between Arrhenius constants and particle size was observed.

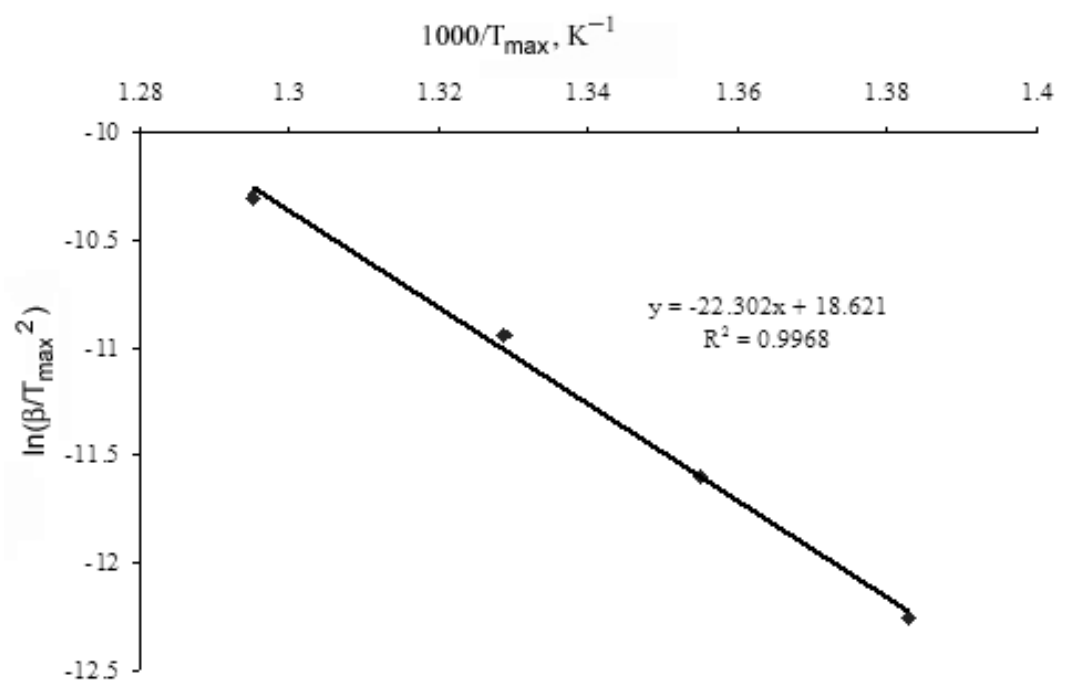

Fig. 9. Kissinger plot of Avgamasya asphaltite (particle size $0.250-0.600 \mathrm{~mm}$ ) for stage 1.

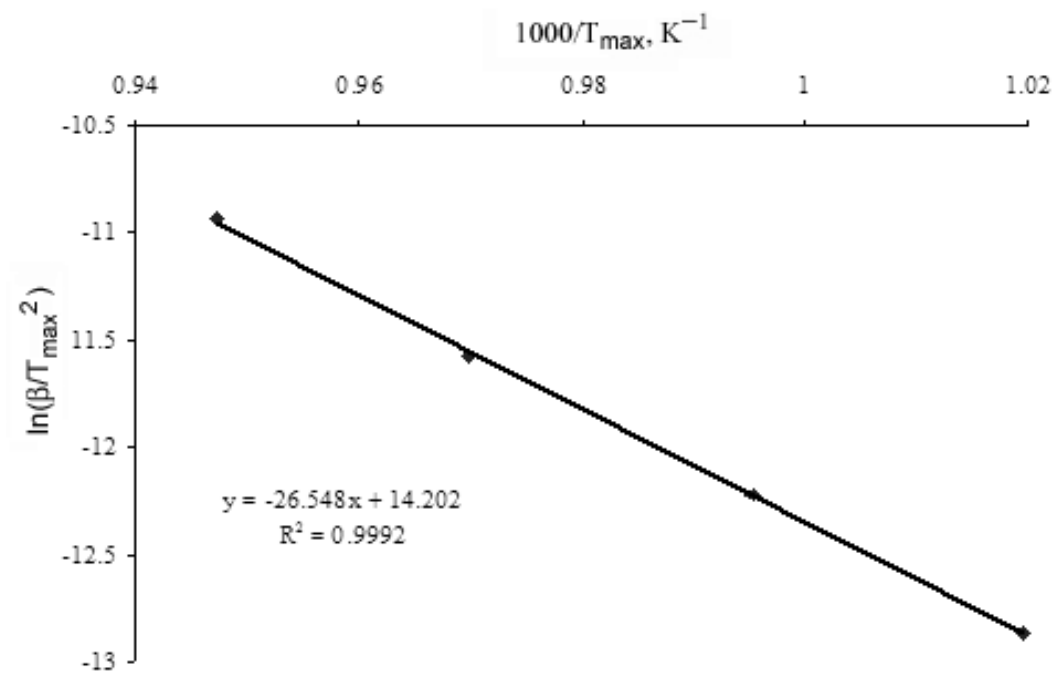

Fig. 10. Kissinger plot of Avgamasya asphaltite (particle size $0.250-0.600 \mathrm{~mm}$ ) for stage 2. 
Table 4. Activation energy and $\ln \mathbf{A}$ values calculated using Kissinger method

\begin{tabular}{|c|c|c|c|c|}
\hline \multirow{2}{*}{$\begin{array}{c}\text { Particle size, } \\
\mathrm{mm}\end{array}$} & \multicolumn{2}{|c|}{ Stage 1 } & \multicolumn{2}{c|}{ Stage 2 } \\
\cline { 2 - 5 } & $\begin{array}{c}E, \\
\mathrm{~kJ} \mathrm{~mol}^{-1}\end{array}$ & $\begin{array}{c}\ln A, \\
\mathrm{~min}^{-1}\end{array}$ & $\begin{array}{c}E, \\
\mathrm{~kJ} \mathrm{~mol}^{-1}\end{array}$ & $\begin{array}{c}\ln A, \\
\mathrm{~min}^{-1}\end{array}$ \\
\hline $0.250-0.600$ & 180.64 & 27.87 & 198.78 & 21.63 \\
$0.125-0.250$ & 195.90 & 30.37 & 175.35 & 11.90 \\
$0.071-0.125$ & 197.40 & 30.62 & 127.76 & 12.81 \\
\hline
\end{tabular}

To compare the results obtained using Kissinger method with the results of Coats-Redfern method, for stage 1, although the kinetic parameters calculated using Kissinger method are slightly higher than those using Coats-Redfern method, it can be said that the results are fairly compatible with each other. On the other hand, for stage 2, kinetic parameters calculated using Coats-Redfern method are nearly two times higher than those using Kissinger method.

The values of kinetic parameters obtained from the proposed reaction kinetic model in the present study appear the lowest ones as compared with literature data. For instance, Altun et al. [9] carried out a similar study and calculated the activation energies of pyrolysis of Silopi asphaltite. In their study, calculated activation energies varied from 50.7 to $61.9 \mathrm{~kJ} \mathrm{~mol}^{-1}$ for stage 1 and from 26.1 to $37.4 \mathrm{~kJ} \mathrm{~mol}^{-1}$ for stage 2 . Also, in that study, the activation energies of samples have a tendency to increase with decreasing particle size. On the other hand, Jaber and Probert [10] applied TG and DTG to two different Jordanian oil shales and calculated the activation energies which varied from 54.7 to $86.2 \mathrm{~kJ} \mathrm{~mol}^{-1}$ for stage 1 and from 149 to $203 \mathrm{~kJ} \mathrm{~mol}^{-1}$ for stage 2, and the activation energy increased with increasing particle size. Kök has studied pyrolysis of oil shale samples in relation to heating rate and temperature using nonisothermal and isothermal analysis [20]. $\mathrm{He}$ found no clear relationship between activation energy and heating rate.

It can be seen that there is no consensus between the researchers on the effect of particle size and heating rate on the kinetic parameters of samples studied.

\section{REFERENCES}

1. Hicyilmaz, C., Altun, N. E. Improvements on combustion properties of asphaltite and correlation of activation energies with combustion results // Fuel Process. Technol. 2006. Vol. 87, No. 6. P. 563-570.

2. Kök, M. V., Bagci, A. S., Ceylan, E., Ozkilic, O. Combustion characteristics of asphaltites // Energ. Source. 2005. Vol. 27, No. 5. P. 417-422.

3. Ballice, L., Saglam, M. Co-pyrolysis of Göynük-oil shale and Sirnak-asphaltite from Turkey and analysis of co-pyrolysis products by capillary GC total stream sampling technique // Fuel. 2003. Vol. 82, No. 5. P. 511-522. 
4. Kök, M. V., Pamir, M. R. Pyrolysis and combustion studies of fossil fuels by thermal analysis methods // J. Anal. Appl. Pyrol. 1995. Vol. 35, No. 2. P. 145156.

5. Kök, M. V. Thermal analysis applications in fossil fuel science: Literature survey // J. Therm. Anal. Cal. 2002. Vol. 68, No. 3. P. 1061-1077.

6. Duz, M. Z., Tonbul, Y., Baysal, A., Akba, O., Saydut, A., Hamamci, C. Pyrolysis kinetics and chemical composition of Hazro coal according to particle size // J. Therm. Anal. Cal. 2005. Vol. 81, No. 2. P. 395-398.

7. Kök, M. V., Pamir, M. R. ASTM kinetics of oil shales // J. Thermal Anal. Cal. 1998. Vol. 53, No. 2. P. 567-575.

8. Steiner, G., Rath, J., Wolfinger, M. G., Staudinger, G. A method to determine the course of heating value and heat production rate of volatiles during the pyrolysis of a solid fuel particle // Thermochim. Acta. 2003. Vol. 398, No. 1-2. P. 59-71.

9. Altun, N. E., Hicyilmaz, C., Kök, M. V. Effect of particle size and heating rate on the pyrolysis of Silopi asphaltite // J. Anal. Appl. Pyrol. 2003. Vol. 67, No. 2. P. 369-379.

10. Jaber, J. O., Probert, S. D. Pyrolysis and gasification kinetics of Jordanian oil shales // Applied Energy. 1999. Vol. 63. P. 269-286.

11. Jing-Song, G., Wei-Biao, F., Bei-Jing, Z. A Study on the pyrolysis of asphalt// Fuel. 2003. Vol. 82, No. 1. P. 49-52.

12. Li, S., Yue, C. Study of pyrolysis kinetics of oil shale // Fuel. 2003. Vol. 82, No. 3. P. 337-342.

13. Tonbul, Y., Saydut, A., Hamamci, C. Pyrolysis kinetics of asphaltites determined by thermal analysis // Oil Shale. 2006. Vol. 23, No. 3. P. 286-293.

14. Wang, H., Yang, J., Long, S., Wang, X., Yang, Z., Li, G. Studies on thermal degradation of poly (phenylene sulphide sulfone)// Polym. Degrad. Stabil. 2004. Vol. 83, No. 2. P. 229-235.

15. Tonbul, Y., Yurdakoc, $K$. Thermogravimetric investigation of the dehydration kinetics of KSF, K10 and Turkish bentonite // Turk. J. Chem. 2001. Vol. 25, No. 3. P. 333-339.

16. Coats, A. W., Redfern, J. P. Kinetic parameters from thermogravimetric data // Nature. 1964. Vol. 201, No. 4914. P. 68-69.

17. Kissinger, H. E. Reaction kinetics in differential thermal analysis // Anal. Chem. 1957. Vol. 29, No. 11. P. 1702-1706.

18. Vyazovkin, S., Wight, C. A. Model-free and model-fitting approaches to kinetic analysis of isothermal and nonisothermal data// Thermochim. Acta. 1999. Vol. 340-341. P. 53-68.

19. Wang, X. L., Yang, K. K., Wang, Y.Z., Wu, B., Liu, Y., Yang, B. Thermogravimetric analysis of the decomposition of poly(1,4-dioxan-2-one)/starch blends // Polym. Degrad. Stabil. 2003. Vol. 81, No. 3. P. 415-421.

20. $K \ddot{o} k, M$. V. Oil Shale: pyrolysis, combustion, and environment: A review // Energy Sources. 2002. Vol. 24, No. 2. P. 135-143.

Presented by M. Kök

Received May 23, 2007 